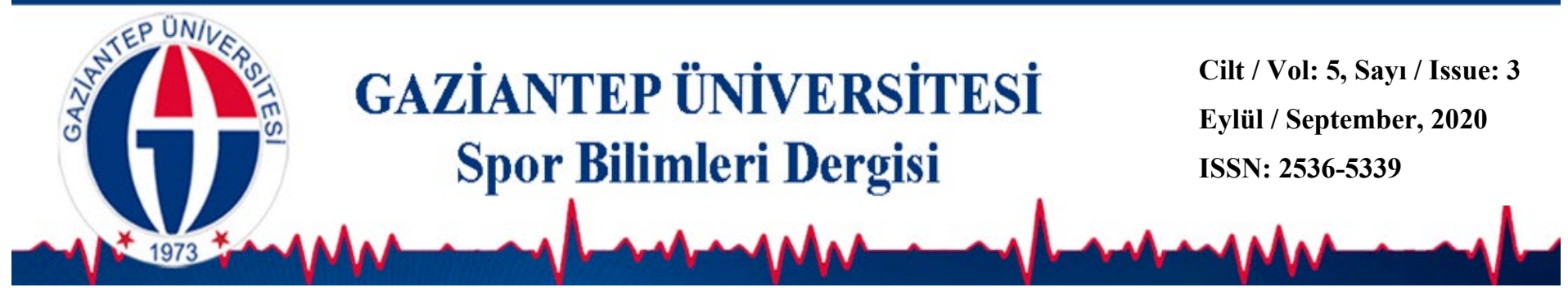

\title{
Başarı İhtiyacı Güdüsünün Girişimcilik Algısı Üzerine Etkisinin İncelenmesi
}

\author{
Fırat ÇETINÖZ1* (i) \\ Zeynep ONAĞ ${ }^{1}$ iD \\ Güliş PANÇALI ${ }^{1}$ (D) \\ ${ }^{1}$ Celal Bayar Üniversitesi, Spor Bilimleri Fakültesi, MANiSA
}

Gizem ERDEN ${ }^{1}$ iD

DOI: $10.31680 /$ gaunjss.763012

Orijinal Makale / Original Article

Geliş Tarihi / Received: 02.07.2020

Kabul Tarihi / Accepted: 11.09.2020

Yayın Tarihi / Published: 14.09.2020

Öz

Bu araştırmanın amacı, spor yöneticiliği bölümü öğrencilerinin Başarı İhtiyacı Güdüsünün (BIGG) Girişimcilik Algıları üzerindeki etkisini incelemektir. Araştırmanın verileri, Manisa Celal Bayar Üniversitesi, Spor Bilimleri Fakültesi Spor Yöneticiliği Bölümü'nde öğrenim gören 111 erkek, 89 kadın olmak üzere toplam 200 kişiden elde edilmiştir. Öğrencilerin BíG'lerini belirlemede, Berry ve Houston (1993)'nın Temel İhtiyaçları Ölçeği "Manifest Needs Questionnaire" (MNQ) kullanılmıştır. Ölçüm aracı 4 boyuttan ve 20 maddeden oluşmaktadır. Araştırmada bu dört boyuttan BiG alt boyutuna ait 5 madde kullanıımıştır. Ölçeğin Türkçe' ye uyarlaması Sivri (2010) tarafından gerçekleştirilmiş olup, ifadelerin spor alanına adaptasyonu Çetinöz (2016) tarafından gerçekleştirilmiştir. Öğrencilerin girişimcilik algılarını belirleyebilmek için ise Yılmaz ve Sünbül (2009) tarafından geliştirilen ve 36 maddeden oluşan üniversite öğrencilerine yönelik girişimcilik ölçeği kullanılmıştır. Regresyon analizi sonucunda başarı ihtiyacı güdüsünün, öğrencilerin girişimcilik algısını \%52,3 açıkladığı $(R 2=, 523$ ve $R=, 723)$ görülmektedir. Bu bağlamda, girişimcilerin tespitinde veya seçiminde bir kişilik özelliği olan BíG yüksek olan bireylerin göz önünde bulundurulmasının iyi olacağı düşünülmektedir.

Anahtar Kelimeler: Ders, eğitim, girişimci

\section{Investigation of The Effect of Need for Achievement on Entrepreneurship Perceptions}

\begin{abstract}
The aim of this study is to examine the effect of need for achievement on entrepreneurship perceptions of sport management department students. The data of the study was collected from a total of 200 people, 111 male, 89 female students at the Department of Sports Management in Sport Sciences Faculty at Manisa Celal Bayar University. Identifying students' need of the achievement perceptions, Beery and Houston's (1993) “Manifest Needs Questionnaire" (MNQ) was used. The measurement tool is composed of 20 items and 4 subdimensions. In this study, 5 items Perception of the Need of the Achivement of sub-dimension was used among these four dimensions. The Turkish adaptation of the scale was carried out by Sivri (2010) and adaptation of the expressions to the sports field was carried out by Çetinöz (2016). To determine the entrepreneurship perceptions of students entrepreneurship scale that consists of 36 items developed by Yılmaz and Sünbül (2009). As a result of the regression analysis, it is seen that the achievement requirement motivation explains the entrepreneurship perception of students by $52.3 \%(R 2=523$ and $R=723$ ). In this context, it is thought that it would be good to consider individuals with high the need for achievement who have a personality trait in the determination or selection of entrepreneurs.
\end{abstract}

Keyword: Lesson, education, entreprenuer

\footnotetext{
* Sorumlu Yazar: Fırat ÇETINÖZ
}

E-mail: firat.cetinoz@cbu.edu.tr 


\section{Giriş}

Üniversiteler ise bir ülkenin iş gücü alanından gelişmişlik düzeyi kadar önemli rol oynamaktadır. $\mathrm{Bu}$ nedenle üniversitelerin tarihi gelişimleri incelendiğinde globalleşen dünyada payını almıştır. Üniversiteler globalleşme ile birlikte yapılarında büyük bir değişim meydana gelmiştir. Bu değişimleri dönemsel olarak özetlemek gerekirse; ilki bilim temelli birinci kuşak üniversitelerden eğitim, ikincisi ise; araştırma temelli ikinci kuşak üniversiteler, son olarak da girişimci ve toplumla bütünleşen üçüncü kuşak üniversiteler olarak yapısal değişimlerini gerçekleştirmişlerdir. Bu değişimi başarılı bir şekilde mümkün kılmak için üniversiteler başta öğrenci merkezli, yenilikçi, yaratıcı fikirleri değerlendirip gerekli adımları atarak önemli görevler üstlenmelidir. Bugün ülkelerin gelişmişlik düzeyleri üniversitelerde yapılan yenilikçi fikirlerin keşfedilmesi ve bu fikirlerin hayata geçirilmesini içine almaktadır. Bu sonuç göz önüne alındığında da Türk Yükseköğretim Sistemi üçüncü kuşak üniversite yapısını kendisine temel almalı ve yapılamasını buna göre tekrardan yapılanmalıdır. Fakat hala ikinci nesil üniversite eğitim anlayışında kalınması ayrıca üçüncü nesil üniversitelere geçiş yapılamamıştır. Üçüncü nesil üniversitelerin inovasyan yapan keşfedilmeyi bekleyen beyinlerin yaratacağı harikalara bağlı olduğu görülmüştür (Karaman, 2018).

Türkiye' de özellikle üniversite düzeyinde her öğrenciye girişimci adayı olarak değerlendirmek ve potansiyellerinin farkına varacakları, sorunları ya da krizleri fırsata dönüştürebilecekleri bilgi ve becerilerle donatmak, yaratıcılıklarını engellemeyip aksine özendirip yetişmelerini sağlamak büyük önem arz etmektedir (Arslan, 2002).

Girişimcilik etkinliği yeni işlerin yaratılmasında ve aynı zamanda yeni işlerin geliştirilmesinde temel kaynak olmakta ve durağan ekonomilerin canlandırılmasında katalizör etkisinin olduğu düşünülen girişimcilik firmaları ve ulusal endüstrilerdeki kişi başına düşen geliri artıran bir niteliktedir (Knight, 2000; Lupkin ve Dess, 1996).

Başarılı girişimcileri belirlemek ve girişimci kişileri diğer kişiler arasından tespit etmek için bireysel farklılıklar üzerinde durulması, bireyin daha önceki iş tecrübesi, başarı isteği (ihtiyacı), üstün sosyal yetenekleri ve kişisel kararlılıkları gibi bireysel faktörlerin incelemesi gerekir (Yılmaz ve Sümbül, 2009; Çavuş ve Akgemci, 2006).

Yapılan araştırmalar parasal faktörlerin girişimciliğe başlamada tüm tatminin faktörlerini tanımladığını bu faktörlerden birinin ise başarı motivasyonun olduğunu göstermektedir (Block ve Koellinger, 2009).

Ayrıca yapılan birkaç çalışmada sürekli olarak girişimcide bulunan öz niteliklerin varlığından söz edilmektedir. Bu öz nitelikler ise inavasyonu tercih etme, potansiyel risk almak ve başarı intiyacı güdüsü olarak tanımlanmaktadır (Steward ve ark, 2003). 
Bunun yanında da Literatürde, kişileri girişimciliğe yöneltebilecek kişisel özelliklere yönelik görüşler ve araştırmalar bulunmaktadır (Karabulut, 2009).

Başarı motivasyonu (güdüsü) ya da başarı ihtiyacı olarak bilinen kavramın temelleri, James (1890)' in gerçekleştirdiği çalışmada; bir mutluk duygusu ve kendine saygının gelişiminde, kişinin kendi iradesiyle belirlediği başarı hedeflerinin nasıl neticelendikleri ile ortaya konmuştur (Stewart, 1995). Başarı ihtiyacı, McCelland ve arkadaşları tarafından (1953), kişinin bireysel performansıyla ortaya koyduğu başarıda mükemmele ulaşma çabası olarak tanımlanmakta ve kişinin bunu bilinçli olarak gerçekleştirmediği, dahası başarı intiyacının bir gereksinim olduğunu belirtilmiştir (Topaloğlu, 2006).

Yüksek derecede başarma ihtiyacına sahip kişiler bireysel gelişimlerine önem vermekte, orta dereceli mantıklı riskler almakta, neticelendirebilecekleri görevlere meyilli olmakta, genellikle kendilerini işlerine adadıkları, kendi istekleri ile sorumluluk adamakta ve ayrıca karşı karşıya kaldıkları zorluklarla mücadele etmektedirler. Yukarıda geçen bireysel farklılıklar farklı yaklaşımlara neden olmuştur ve bunun temelinde ise başarı ihtiyacının birden fazla bağımsız değişkenden meydana geldiği görüşü etkili olmuştur (Sagie ve Elizur, 1999). Cassidy ve Lynn (1989) ise başarı ihtiyacının temel faktörlerini üstünlük, statü tutkusu, rekabetçilik, iş etiği, para ve varlık düşkünlüğü olarak belirlemişlerdir (Cassidy ve Lynn, 1989).

Mevcut araştırma ile lisans düzeyinde spor eğitimi alan ve almayan üniversite öğrencilerinin girişimcilik özelliklerini tespit etme, girişimcilik potansiyellerini kullanabilme becerisini değerlendirme ve bu anlamda diğer daha önceden yapılmış araştırmalarla karşılaştırma amacıyla gerçekleştirilmiştir. Ülkemizde yapılan girişimcilik araştırmalarına bakıldığında devlet üniversitelerinde yapılan çalışmaların başı çektiği görülmektedir. Araştırmada aynı üniversitenin farklı fakülte ve yüksekokulunda eğitim gören öğrencilerin girişimcilik düzeylerini de mukayese etmektedir. Araştırma, üniversite öğrencilerinin girişimcilik eğilimleri ne düzeydedir sorusuna da cevap aramaktadır.

\section{Literatür Taraması}

\section{Başarı İhtiyacı Güdüsü ve Girişimcilik}

Geleneksel olarak başarı motivasyonu kavramsallaştırılacak olursa; başarı ve mükemmelliğe ulaşmak için bireysel olarak zorluklarla yüz yüze gelme eğilimi olarak tanımlanabilir. Bu eğilimler belirsizlik toleransı, kesin olmayan durumlar ile yüzleşme, hesaplanamayan riskiler, performans sergilemek için çabalamak ve henüz tam olarak 
belirlenmiş zor amaçları oluşturmak olabilir. Bunlara ek olarak geleneksel ve yaratıcı problem çözme ve kişisel sorumluk üstlenme gibi davranışları içi alır (Johnson, 1990; Sagie, 1994).

Başarı motivasyonu ile girişimcilik kavramlarını birlikte kullanıldığı birçok çalışma vardır. Araştırmaların büyük bir kısmı bu yapının ölçülebilir ve kavramlaştııııması noktasına yoğunlaşmıştır(Collince ve ark, 2004;Sagie, 1994). Diğer bölümdeki araştırmalar ise; girişimci ve girişimci olmayanlar ya da başarı motivasyonu ile girişimcilik davranışı arasındaki ilişkiyi açıklama eğilimdedir (Brockhaus, 1982; Johnson, 1990; Naffziger ve ark, 1994). Henüz diğer grubu oluşturan araştırmalar finansal kazanım başarısı ya da firmaların gelişimlerini sağlayan grupların performans çıktıları ile bireysel başarı intiyacı güdüsünü etkilerini incelememişlerdir (Kolvereid, 1992). Daha az çalışmanın dikkatini çıktılar ile ilgili firma düzeyleri, bireysel davranışlar odağını oluşturmaktadır. Sorunun merkezinde başarı motivasyonun etkisinin bu düzey ve davranışlara ne kadar etkide bulunduğudur (Johnson, 1990; Collins, 2004; Kolvereir,1992).

\section{Yöntem}

\section{Araştırmanın Modeli}

Mevcut araştırmada nicel araştırma modellerinden betimsel ve ilişkisel tarama modeli benimsenmiş̧ir.

\section{Evren ve Örneklem}

Bu araştırmanın evrenini T.C. Manisa Celal Bayar Üniversitesi, Spor Bilimleri Fakültesi, Spor Yöneticili Bölümü'nde 2017-2018 Öğretim yılında lisans düzeyinde öğrenim gören 286 erkek öğrenci ve 200 kız öğrenci olmak üzere toplam 486 öğrenci oluşturmaktadır. Araştırmanın örneklemini ise bu evren içerisinden rastgele olarak belirlenen 111 erkek, 89 kadın olmak üzere toplam 200 kişi oluşturmaktadır.

\section{Veri Toplama Araçları}

Öğrencilerin başarı intiyacı güdüsünü (BIG) belirlemede, Berry ve Houston (1993)'nın Temel İhtiyaçları Ölçeği "Manifest Needs Questionnaire" (MNQ) kullanılmıştır. MNQ ölçeği 4 boyuttan ve 20 maddeden meydana gelmektedir. Araştırmada bu dört boyuttan BiG alt boyutuna ait 5 madde kullanılmıştır. Ölçeğin Türkçe' ye uyarlaması Sivri (2010) tarafından gerçekleştirilmiş olup, ifadelerin spor alanına adaptasyonu Çetinöz (2016) tarafından gerçekleştirilmiştir. 
Öğrencilerin girişimcilik algılarını belirleyebilmek için ise Yılmaz ve Sünbül (2009) tarafından geliştirilen tek alt boyuttan meydana gelen ve 36 maddeden oluşan üniversite öğrencilerine yönelik girişimcilik ölçeği kullanılmıştır.

Katıımcıların (öğrencilerin) demografik değişkenlerini belirlemek amacı ile yaş, cinsiyet, okudukları sınıf ve girişimcilik dersini seçmeli olarak okuyup okumadıkları belirlemek amacı ile toplam 4 soru sorulmuştur.

\section{Verilerin Toplanması}

Araştırmada kullanılan veriler fakülte yönetiminin izni doğrultusunda öğrencinin serbest zamanlarında (kantin, kafeterya, kütüphane v.b.) ya da ayrıca öğretim elemanında alınan izin ile ders saati başlangıçlarında ya da ders saati sonunda sınıf ortamında anketlerin araştırmacı tarafından yüz yüze doldurulması ile elde edilmiştir.

\section{Verilerin Analizi}

Öncelikle ölçeme araçlarının geçerliği-güvenirliğini onaylamak için KaiserMeyer-Olkin testi değerleri tespiti ve cronbach alpha değerleri tespiti yapılmıştır. Daha sonra verilerin düzgün dağılım gösterip göstermediğinin tespiti için KolmogorovSimirnov testi uygulanmıştır. Başarı ihtiyacı güdüsünün girişimcilik algısını olan etkisini ortaya koymak için öncelikle aralarındaki ilişkinin tespiti için pearson korelasyon testi hemen ardında etkisini ortaya koymak içinse doğrusal regresyon analizi tatbik edilmiştir.

\section{Bulgular}

Bu bölümde ölçme araçlarının geçerliği-güvenirliği hakkında bilgi verilmektedir. Bunun yanında katılımcıların demografik değişkenleri ile katılımcılardan elde edilen verilerin dağııımı hakkında bilgiler paylaşılmaktadır. Ayrıca ölçme araçlarının bir birleri arasındaki ilişkisi ve bir birine olan etkileri hakkında sayısal veriler verilmektedir.

\section{Araştırmanın Modeli}

Mevcut araştırma modeli olarak nicel yöntem benimsenmiştir. Nicel yöntem içinde var olan tarama modeli uygulanmıştır.

\section{Araştımanın Geçerliği}

Girişimcilik ölçeğindeki 36 maddesi kendi arasında ve ölçek toplam puanları ile tutarlı bir sonuç ortaya koyması nedeniyle tüm maddelere faktör analizi yapılmıştır. 
Verilerin faktör analizine uygunluğu Kaiser-Meyer-Olkin ile analiz edilmiştir. Temel Bileşenler analizinde Kaiser-Meyer-Olkin (KMO) değeri 0,921 olarak tespit edilmiştir. Bu sonucun literatür ve uzman görüşlerine göre yeterli olduğu söylenebilir (Murphy ve Davidshofer, 1991). Girişimcilik ölçeğinin 36 maddesinin tek bir alt boyutta toplandığını ve bu maddelerin faktör yüklerinin 0,577 ile 0,771 arasında değişkenlik gösterdiği görülmüştür.

Başarı intiyacı alt ölçeğinin 5 maddesi içinde ölçek toplam puanları ile tutarlı bir sonuç ortaya koyması nedeniyle tüm maddelere faktör analizi yapılmıştır. Verilerin faktör analizine uygunluğu Kaiser-Meyer-Olkin ile analiz edilmiştir. Temel Bileşenler analizinde Kaiser-Meyer-Olkin (KMO) değeri 0,841 olarak tespit edilmiştir. Bu değerinde literatür ve uzman görüşlerine göre (Murphy ve Davidshofer, 1991) yeterli olduğu söylenebilir. Ayrıca başarı intiyacı alt ölçeğinin 5 maddesinin aynı boyut içerisinde bulunduğu ve faktör yüklerinin 0,622 ve 0,733 arasında değişkenlik gösterdiği tespit edilmiştir.

\section{Araştırmanın Güvenirliği}

Bir ölçüm aracının güvenilirliği çeşitli yöntemlerle hesaplanmakla birlikte, içlerinde en yaygın olanı içsel tutarlılık (internal consistency) yönetimidir. Çalışmamızda bu yöntemde hesaplanan cronbach alpha güvenilirlik ölçütü kullanılmıştır. Cronbach alpha değeri, 0 ile 1 arasında değişen bir katsayıdır ve bu sayı 1'e yaklaştıkça ölçeğin güvenilirliğinin yüksek olduğu düşünülmektedir. Üniversite öğrencileri girişimcilik algısını belirlemek için kullanılan ölçeğinin güvenirlik katsayısı 0,956 (36 madde) olarak hesaplanırken başarı ihtiyacı güdüsün cronbach alpha değeri 0,864 (5 madde) olarak tespit edilmiştir.

\section{Katılımcılar Hakkında Bilgiler}

Tablo 1: Katılımcıların cinsiyetleri, öğretim şekilleri ve girişimcilik dersi alıp almadıklarına dair frekans dağılımı ve yüzdelik dilimleri

\begin{tabular}{cccc}
\hline \multicolumn{2}{c}{ Değişken } & Frekans Değeri & Yüzdelik Dilim \\
\hline \multirow{3}{*}{ Einsiyet } & Erkek & 111 & 55,5 \\
& Kadın & 89 & 44,5 \\
& Toplam & 200 & 100 \\
\hline \multirow{3}{*}{ Öğretim Şekli } & Örgün & 116 & 58,00 \\
& II. Öğretim & 84 & 42,00 \\
& Toplam & 200 & 100 \\
\hline Girişimcilik & Evet & 45 & 22,50 \\
Dersi Alanlar & Hayır & 155 & 77,50 \\
& Toplam & 200 & 100 \\
\hline
\end{tabular}


Yukarıdaki tabloda araştırmaya katılım gösteren Manisa Celal Bayar Üniversitesi, Spor Yöneticiliği Bölümü lisans öğrencilerinin demografik bilgileri paylaşılmıştır. Buna göre; katılımcıların 111 'i $(\% 55,5)$ erkek ve 89'u $(44,5)$ kadın olmak üzere toplamda 200 kişidir. Bu 200 katılımcının 116’sı (\%58) örgün öğretim öğrencisiyken 84'ü (\%42) II. Öğretim öğrencisidir. Bu 200 katılımcıdan 155’i (\%77,50) girişimcilik dersi görmezken, $45^{\prime} \mathrm{i}(\% 22,5)$ girişimcilik dersi almıştır.

\section{Araştırmanın Verilerinin Dağılımı}

Hem girişimcilik algısı (36 madde) hem de başarı ihtiyacı güdüsünün (5 madde) Kolmogorov-Simirnov testi sonucuna göre iki ölçeğin $p=0,000$ olarak tespit edilmiştir. Mevcut değer $p<=0,05$ olması neden ile verilerin düzgün dağılmadığı söylenebilir. Ayrıca yapılan skewness ve kurtosis analizlerinde değerlerin $-1,5$ ve $+1,9$ değerleri arasında değişkenlik gösterdiği tespit edilmiştir.

\section{Değişkenler Arası İlişkiler}

Tablo 2: Girişimcilik Algısı ve Başarı İhtiyacı Güdüsü Arasındaki Korelasyon

\begin{tabular}{lcc}
\hline Değişkenler & Başarı İhtiyacı Güdüsü & Girişimcilik algısı \\
\hline Başarı İhtiyacı Güdüsü & 1 &, $723^{* *}$ \\
Girişimcilik algısı &, $723^{* *}$ & 1 \\
\hline${ }^{* *} p<0,01$ &
\end{tabular}

Sürekli değişkenlerin arasındaki bire bir ilişkileri gösteren korelasyon katsayıları Tablo 2'de verilmiştir. Korelasyon katsayılarının yorumlanmasında $r=1-0,70$ arası olması yüksek ilişkiye işaret ederken $r=0,70-0,30$ arası orta düzeyde bir ilişkiye ve $r=0,30-0$ arası düşük ilişkiye işaret etmektir (Büyüköztürk 2010). Buna göre başarı ihtiyacı güdüsü ile girişimcilik algısı arasında $r=0,723(p<0,01)$ ve pozitif yönlü yüksek ilişki tespit edilmiştir. Bireyin başarı ihtiyacı güdüsü arttıkça girişimcilik algısının arttığı söylenebilir.

\section{Başarı İhtiyacı Güdüsünün Girişimcilik Algısına Etkisi}

Tablo 3: Başarı İhtiyacı Güdüsünün Yordanmasına İlişkin Regresyon (Doğrusal) Analizi

\begin{tabular}{cccccc}
\hline $\begin{array}{c}\text { Değişken } \\
\text { (sabit) }\end{array}$ & B & Standard Hata & $\beta$ & T & P \\
\hline $\begin{array}{c}\text { Başarı İhtiyacı } \\
\text { Güdüsü }\end{array}$ &, 559 &, 038 &, 723 & 14,730 &, 000 \\
\hline
\end{tabular}


Tablo 3 incelendiğinde istatistiksel düzeyde anlamlı sonuçlar verdiği tespit edilmiştir $(R=, 723, R 2=, 523$ ve $p<0,019)$. Regresyon analizi (Doğrusal) sonucunda başarı ihtiyacı güdüsünün, öğrencilerin girişimcilik algısını \% 52,3 oranında açıkladığı görülmüştür.

\section{Tartışma ve Sonuç}

Ülkelerin ekonomik gelişiminin temelinde başarı veya kazanımların önemli payının olduğu söylenebilir (Schatz, 1965). McCelland in başarı ihtiyacı güdüsü teorisi bir ayağını da toplumun ekonomik refahı oluşturmaktadır. McClelland, araştırmaları neticesinde, ülkenin genel ekonomik vaziyeti ile başarısı arasında bir ilişkinin olduğunu kanaatine varmıştır. Eski medeniyetler bu açıdan incelendiği zaman, ulusal düzeyde zenginliğin ya da varlığın ve iktisadi kalkınmanın ülke insanının başarı çabasından ileri gelebileceğini düşünmüştür (Davis ve David, 1997 Aktaran Pekel 2001).

Başarıya fazlasıyla gereksinimi olan bireyler, girişimci olma eğilimi gösterebilmektedir. Bu tarz eğilime sahip olan bireylerde rekabet içinde bulunduğu kişilerden daha iyi işler çıkarmaya meyilli ve mantıklı iş riskleri almayı tercih ettikleri bildirilmektedir (De Cenzo David ve Robbinis, 1996 Aktaran Pekel 2001).

Bugüne kadar elde edilen sonuçların büyük bir kısmının McCelland' in başarı motivasyonun (başarı ihtiyacı) sonuçlarını destekler nitelikte olduğu söylenebilir. Bizimde gerçekleştirdiğimiz çalışmanın sonuçları da bu yönde olmuştur. Carland ve ark, 1984; Steart ve ark, 2003; Wu ve ark, 2007; Carraher ve ark, 2010 iki kavram arasında pozitif yönlü bir ilişkisinin olduğunu belirtmek suretiyle araştırmayı destekler nitelikte olduğu söylenebilir.

Başarı güdüsü özellikle girişimcilik rolünün hem mesleki seçim aşamasında hem de performans gösterme aşamasında ilişkilidir. Örnek olarak girişimcinin başarısında başarı ihtiyacı güdüsünün pozitif yöndeki ilişkisini McCelland (1961) ve diğerleri (Schrage, 1965; Lynn, 1969; Singh, 1969; Dart, 1971; Nandy, 1973; Durand, 1975; Roberts, 1972; Kock, 1965; Wainer ve Rubin, 1969) rapor etmişlerdir (Steward ve ark, 2003).

Ayrıca girişimci ile girişimci olmayan bireyler arasında yapılan çalışmada girişimci bireylerin başarı intiyacı güdüsünün daha yüksek olduğunu istatistiki olarak ortaya konulmuştur (Ahmed, 1984).

Wu, Matthews ve Dagher (2007) yapmış oldukları çalışmada başarı ihtiyacı güdüsü ve girişimcilik algısı arasında pozitif yönlü bir ilişki rapor etmişlerdir (Wu ve Dager, 2007). Raporunda, arasındaki ilişkiyi ( $r=70)$ yüksek olarak belirtmiştir. Ayrıca 
başarı intiyacı güdü ile girişimcilik algısı arasındaki pozitif yönlü korelasyon olduğunu Merrite (1999) ile Zhao ve Wu (2014) rapor etmişlerdir (Sabiu ve ark, 2018). Sabiu, ve ark. (2018) yapmış oldukları çalışmalarında ise başarı intiyacı güdüsü ve girişimcilik arasındaki korelasyonun $(p<0,01 r=, 527)$ orta düzeyde tespit etmişlerdir. Bu noktadan hareketle başarı intiyacı güdüsü yüksek bireylerin girişimcilik algılarının yüksek olduğu düşünülebilir. Hansemark (1998) girişimcilik davranışında ve başarısında başarı ihtiyacı güdüsünün teşvikinden bahsetmektedir (Hansemark, 1998 ).

Gerçekleştirilen birçok çalışmada kişisel bir özellik olan başarı intiyacı güdüsünün olumlu etkisinden bahsedilmekte ya da kullanıldığı bağımlı değişken ile pozitif yönlü bir ilişkisine vurgu yapılmakta veya bu bağımlı değişken ile istatistiksel düzeyde anlamlı farkının bulunduğu ileri sürülmektedir. Girişimcilik alanında yapılan birçok çalışmanın kişisel özellikleri ön plana çıkardığı söylenebilir. Bu noktada hareketle gerçekleştirilen araştırmada; girişimcilerin seçiminde ya da girişimci adaylarının belirlenmesinde bir kişilik özelliği olan başarı ihtiyacı güdüsü yüksek olan bireylerin göz önünde bulundurulmasının iyi olacağı düşünülmektedir.

\section{Kaynaklar}

Ahmed, SU. (1984). Nach, Risk-Taking Propensity. Locus of Control and Entrepreneurship Person individ. Difl. ; 6 (6) $781 . \quad-782$. doi:Https://doi.org/10.1016/0191-8869(85)90092-3

Arslan, K. (2002). Üniversiteli Gençlerde Mesleki Tercihler ve Girişimcilik Eğilimleri. Doğuş Üniversitesi Dergisi, 6, 1-11.

Block, J. ve Koellinger, P. (2009). I Can't Get No Satisfaction-Necessity Entrepreneurship and Procedural Utility. KYKLOS, 62(2), 191-209

Büyüköztürk, Ş. (2010). Sosyal bilimler için veri analizi el kitabı (İstatistik araştırma deseni, spss uygulamaları ve yorumları) 11.Baskı. Pegem Akademi,; ISBN 978975-6802-74-8,

Carland, JW., Hoy F., Boulton, WR. \& Carland, JAC.(1984). Differentiating Entrepreneursf Rom Small Business Owners: A Conceptualization. Academy of Management Review, 9 (2), 354-359. doi :https://doi.org/10.5465/amr. 1984.4277721

Carraher, SM., Buchanan, JK. \& Puia, G. (2009). Entrepreneurial Need for Achievent in China, .Latvi, and USA. Baltic Journal of Management, 5 (3), 378-396. 
Cassidy, T. ve Lynn, R.(1989). A Multifactorial Approach to Achievement Motivation: The Development of A Comprehensive Measure. Journal of Occupational Psychology, 62(4), 301-312.

Collins, CJ., Hanges PJ., \& Locke EA. The Relationship of Achievement Motivation to Entrepreneurial Behavior: A Meta-Analysis. Human Performance, 17 (1), 95117. DOI: https://doi.org/10.1207/S15327043HUP1701_5

Çavuş, FM. ve Akgemci, M. (2006). İşletmelerde Personel Güçlendirmenin Örgütsel Yaratıcılık ve Yenilikçiliğe Etkisi: İmalat Sanayiinde Bir Araştırma. Selçuk Üniversitesi Sosyal Bilimler Enstitüsü, 20, 229-244

Hansemark, OC. (1998). The Effects of An Entrepreneurship Programme On Need For Achievement and Locus of Control of Reinforcement. International journal of Entrepreneurial Behaviour and Research, 4(1) 28-50, DOI: 10.1108/13552559810203957.

Johnson, B.(1990). Toward a Multidimensional Model of Entrepreneurship: The Case of Achievement Motivation and The Entrepreneur. Entrepreneurship Theory and Practice, 14 (3), 39-55. doi: https://doi.org/10.1177/104225879001400306

Karabulut, T. (2009). Üniversite Öğrencilerinin Girişimcilik Özelliklerini ve Eğilimlerini Belirlemeye Yönelik Bir Araştırma. Marmara Üniversitesi I.I.B.F. Dergisi, 26 (1), 331-356.

Karıman, E. ve Eliöz, M.(2018). Girişimci Eğilimi Göstermeyen Üniversite Öğrencilerinin Girişimcilik Potansiyelinin Araştırılması. OMU Journal of Education Faculty, 37(2): 195-209 doi: 10.7822/omuefd.426664

Knight, G. (2000). Entrepreneurship and Marketing Strategy: The SME Under Globalization. Journal of International Marketing, 8 (2): 12-32, ISSN 1069-031X. doi: https://doi.org/10.1509/jimk.8.2.12.19620

Kolvereid, L.(1992) Growth Aspirations Among Norwegian Entrepreneurs. Journal of Business Venturing, 7 (3), 209-22. URI: http://hdl.handle.net/123456789/1762 Lupkin, GT. ve Dess, GG. (1996). Clarifying The Entrepreneurial Orientation Construct and Linking it to. Performance Academy of Management Review, 21(1), 135-172. doi: https://doi.org/10.5465/amr.1996.9602161568

Pekel, NH. (2001). İşletmelerde Motivasyon-Verimlilik İlişkisi (Devlet Hava Meydanları İşletmesi Antalya Hava Limanı Çalışanları Arasında Bir Örnek Olay Araştırması). T.C. Süleyman Demirel Üniversitesi, Sosyal Bilimler Enstitüsü, İşletme Anabilim Dalı, Yüksek Lisans Tezi. 
Sabiu, IT., Abdullah, A., Amin, A. \& Tahir, IM.(2018). An Empirical Analysis of The Need For Achievement Motivation in Predicting Entrepreneurial Persistence in Bumiputra Entrepreneurs in Terengganu, Malaysia. Orientations: A Comparative Exploration of United States and Russian Entrepreneurs. Journal of Small Business Management, 41(1), 27-46. doi: https://doi.org/10.1504//JBG.2018. 089867

Sagıe, A. ve Elızur, D.(1999). Achievent Motive and Entrepreneurial Orientation: A Structural Analysis. Journal of Organization Behavior, 20 :375-387. DOI: https://doi.org/10.1002/(SICI)1099-1379(199905)20:3<375::AIDJOB884>3.0.CO $; 2-Y$

Sagie, A.(1994). Assessing achievement motivation: construction and application of a new scale using Elizur's multifaceted approach. The Journal of Psychology, 128 (1), 51-61. doi:https://doi.org/10.1080/00223980.1994.9712711

Schatz, SP. (1965). Achievent and Economic Growt: A Critique. The Quaterly Journal of Economics, 7 (2), 234-245

Stewart, WH., Carland, JC., Carland, JW., Watson, WE. \& Sweo, R.(2003). Entrepreneurial Dispositions and Goal Orientations: A Comparative Exploration of United States and Russian Entrepreneurs. Journal of Small Business Management, 41(1), 27-46. doi:https://doi.org/10.1111/1540-627X.00065

Topaloğlu, T. (2006).Girişimcinin Motivasyonel ve Bilişsel Kişilik Özellikleri: Girişimci ve Yöneticilerin Öğrenilmiş Gereksinimleri ve Kontrol Odaklarının Kıyaslamasına Yönelik Bir Araştırma. T.C. Dokuz Eylül Üniversitesi, Sosyal Bilimler Enstitüsü, İşletme Anabilim Dalı, Yönetim Organizasyon Programı, Yüksek Lisans Tezi,

Wu, S., Matthews, L. \& Dager GK. (2007). Need For Achievement, Business Goals, and Entrepreneurial Persistence. Emerald Group Publishing Limited, 30 (12), 928-941. doi: 10.1108/01409170710833358

Yılmaz, E. ve Sünbül, AM.(2009). Üniversite Öğrencilerine Yönelik Girişimcilik Ölçeğinin Geliştirilmesi. Selçuk Üniversitesi Sosyal Bilimler Enstitüsü Dergisi, 21, 195-203 